\title{
Bustier Ditinjau dari Bahan Pelapis (Interfacing) dan Teknik Pengepresan
}

\author{
Agilistiya Rahayu', Muhammad Amin², Aulia Agus ${ }^{3}$, Wahda $^{4}$ \\ 1, 2, 3, ${ }^{4}$ Fakultas Ekonomi, Universitas Muhammadiyah Sorong, Indonesia \\ Email. agilistya685@gmail.com
}

\begin{abstract}
ABSTRAK
Pengepresan lapisan dalam berperan penting terhadap hasil bustier. Ketersediaan mesin press pada modiste dan Mahasiswa Prodi Pendidikan Tata Busana terbatas. Setrika listrik manual merupakan alat yang biasa digunakan untuk melakukan pengepresan, berbagai bahan digunakan untuk membuat bustier. Karakteristik setiap bahan yang berbedabeda terutama bila terkena panas. Masalah yang sering timbul setelah pengepresan lapisan dalam akibat panas yang tidak sesuai diantaranya timbul gelembung, warna kain berubah, arah serat berubah, dan sisa lem timbul pada bagian baik kain. Muncul berbagai teknik pengepresan lapisan dalam, yaitu dilapisi kain basah, disemprot air, dilapisi kertas, dan tanpa dilapisi apapun yang memiliki keunggulan dan kelemahan masing-masing. Bermacam-macam teknik pengepresan lapisan dalam diharapkan dapat memperkecil masalah yang timbul pada pengepresan lapisan dalam. Penelitian ini bertujuan untuk mengetahui ada tidaknya perbedaan hasil bustier menggunakan empat teknik pengepresan lapisan dalam dan mengetahui teknik pengepresan dalam manakah yang menghasilkan hasil terbaik.
\end{abstract}

Kata Kunci : Bustier, Lapisan Dalam, Teknik Pengepresan Lapisan Dalam.

\begin{abstract}
Inner layer pressing plays an important role in bustier results. Availability of press machines in fashion and fashion education study program students is limited. Manual electric iron is a tool commonly used for pressing, various materials are used to make bustiers. The characteristics of each material are different, especially when exposed to heat. Problems that often arise after pressing the inner layer due to inappropriate heat include bubbles appearing, the color of the fabric changes, and the remaining glue appears on the good parts of the fabric. Various inner-layer pressing techniques emerged, namely coated with body cloth, sprayed with water, coated with paper, and without any coating which had their respective advantages and disadvantages. A variety of inner-layer pressing techniques are expected to minimize the problems that arise in the inner-layer pressing. This study aims to determine which technique produces the best results.
\end{abstract}

Keywords : Bustier, Inner Layer, Inner Layer Pressing Technique

\section{PENDAHULUAN}

Busana merupakan helai pakaian yang melekat di tubuh manusia dan selaludikenakan dalam suatu apapun. Busana sangat penting dalam suatu kehidupan karena busana berguna untuk melindungi diri sebagai alat pelindung kulit terhadap sengatan sinar matahari, pelindung dari udara dingin (faktor kesehatan), sebagai alat perhiasan untuk memperindah dan mempercantik diri, dan tentunya nyaman dikenakan saat beraktifitas (Khoiriyah and Musdalifah 2020). Busana merupakan kebutuhan manusia yang pada awalnya hanya mempunyaifungsi sebagai alat 
pelindung tubuh dari pengaruh luar, seiring dengan perkembangan sumber daya manusia, penggunaan busana mempunyai fungsi sebagai salah satu fungsi sarana komunikasi nonverbal yaitu sebagai penyampai pesan dalam arti busana yang dipakai oleh seseorang dapat mempengaruhi reaksi dari orang lain yang melihatnya, sebagai ekspresi identitas pribadi, busana juga mempunyai fungsi untuk membantu menutupi kekurangan bagian-bagian tubuh tertentu dari si pemakai(Apriliani et al. 2016).Secara khusus tujuan program keahlian tata busana adalah membekali peserta didik dengan keterampilan, pengetahuan dan sikap agar kompeten : (a).Mengukur, membuat pola, menjahit dan menyelesaikan busana, (b).Memilih bahan tekstil dan bahan pembantu secara tepat, (c).Mendesain berbagai jenis busana sesuai dengan kesempatan, (d).Menghias busana sesuai desain, (e).Mengelola usaha dibidang busana(Fergusson et al. 2013).

Bustier merupakan pakaian dalam yang mempunyai fungsi yaitu membentuk tubuh agar lebih proporsional pada saat memakai kebaya. Bustier tidak hanya dikenakan dengan kebaya tetapi bisa juga dengan gaun. karakteristik khususnya adalah mempunyai bentuk yang tegas pada shiluet bustier. "Bentuk tegas dari bustier pengaruh dari sistem pola yang digunakan, bahan pelapis yang digunakan untuk melapisi bahan utama pembuatan bustier juga salah satu faktor yang membuat bentuk shiluet dari bustier terlihat tegas.Bustier dapat diartikan dengan busana dalam atau busana luar karena sudah berubahnya fungsi busana tersebut. Bustier pada abad ke 19 merupakan busana dalam tapi pada tahun 1980-an bustier sudah berubah fungsi menjadi busana luar.(Napitu 2011)

Busana dalam merupakan busana yang melekat langsung pada kulit, dipakai sebelum memakai busana luar. Busana dalam memiliki fungsi yang berbeda-beda sesuai dengan kegunaannya. Busana yang langsung menutup kulit, seperti celana dalam, singlet, rok dalam, bebe dalam, longtorso, bustier yang berfungsi untuk melindungi bagian-bagian tubuh manusia. Pengepresan Lapisan dalam (fusing) adalahproses merekatkan (memanaskan dan mengepres) komponen-komponen kecil pada pakaian seperti collar, cuff, centerline, dan sebagainya dengan material atau bahan pelapis (interfacing) yang berfungsi sebagai pembentuk untuk membuat pakaian lebih kaku, kuat dan mengokohkan bagian-bagian tertentu.Namun seiring dengan perkembangan peradaban manusia, busana sudah memiliki fungsi yang kompleks yakni untuk memperindah diri sehingga menambah rasa percaya diri bagi yang memakainya (Penelitian 2008).

Observasi yang telah dilakukan peneliti pada 3 tempat industri busana menengah ke bawah di Semarang dan mahasiswa Program Studi Pendidikan Tata Busana angkatan 2011 di Universitas 
Negeri Semarang (UNNES). Tujuan dari diadakannya pelatihan ini adalah untuk mengetahui perbedaan hasil bustier ditinjau dari bahan pelapis (interfacing) dan teknik pengepresan lapisan dalam. Dengan tercapainya tujuan diatas, diharapkan hasil pelatihan ini dapat memberikan manfaat berupa : 1) Bagi penulis dapat menambah wawasan dan pengetahuan peneliti yang berkaitan dengan teknik pengepresan bustier. 2) Bagi para akademisi, dapat digunakan untuk menambah ilmu pengetahuan dalam bidang busana, khususnya teknik pengepresan pembuatan bustier pada mata kuliah Manajemen Adibusana. 3) Bagi penelitian lanjutan, diharapkan dapat digunakan sebagai sarana informasi awal bagi peneliti yang hendak meneliti bidang kajian yang sama.

\section{METODE PENELITIAN}

Metode penelitian ini adalah metode kualitatif yaitu observasi yang dibuat dengan menggunakan konstruksi pola sistem chung hwa, data yang dianalisis adalah data primer yang diperoleh dengan menggunakan instrumen pengamatan dari 3 orang pengamat dengan menggunakan hasil fitting dengan pemberian nilai 3 untuk kategori terbaik, 2 untuk kategori cukup, dan 1 untuk kategori kurang. Data dikumpulkan menggunakan angket, observasi, dan dokumentasi.

\section{HASIL DAN PEMBAHASAN}

Menjahit bustier merupakan pengetahuan yang harus dikuasai agar dapat menjahit bustier dengan baik dan benar (Di and Negeri 2014). Ketersediaan mesin press pada modiste dan mahasiswa Prodi Pendidikan Tata Busana, terbatas karena biaya penggunaan alat yang tinggi, observasi dilakukan di Dian Saputra Fashion Designer, Purnama Tailor, dan Mahasiswa Pendidikan Tata Busana angkatan 2011, bahwa alat yang biasa digunakan untuk melakukan pengepresan lapisan dalam yaitu seterika listrik manual. Pemroduksi busana kurang memahami tentang suhu yang tepat saat penggunaan seterika listrik manual yang digunakan untuk melekatkan lapisan dalam pada kain mereka hanya menggunakan perkiraan untuk menggunakan seterika listrik manual.

Bahan utama yang biasa digunakan untuk pembuatan bustier yaitu jenis serat polyester yang mempunyai karakteristik mudah berubah bentuk apabila mengalami suhu yang terlalu tidak tepat. Teknik pengepresan lapisan dalam terdiri atas bermacam-macam teknik yang memiliki hasil yang berbeda pada bahan utama. 
Pembatasan masalah diperlukan untuk menetapkan permasalahan yang telah di identifikasi, permasalahan yang perlu dibatasi dalam penelitian ini adalah : 1) Alat press yang digunakan adalah seterika listrik manual. 2) Lapisan dalam (interfacing) yang digunakan kain gula. 3) Bahan utama yang digunakan dalam pembuatan bustier yaitu kain dari serat polyester yaitu tenunan satin, dengan merk dagang satin velvet. 4) Kertas yang digunakan adalah kertas roti berwarna putih transparan. 5) Kain yang digunakan untuk melapisi saat pengepresan yaitu kain cotton campuran merk dagang arrow. 6) Teknik yang digunakan dalam pengerpresan lapisan dalam yaitu dilapisi kertas, tanpa dilapisi kertas, disemprot air, dan dilapisi kain basah.

Masalah yang timbul akibat penggunaan alat manual sering ditemukan terutama para mahasiswa bidang busana yang belum menguasai pengalaman mengenai pengepresan lapisan dalam. Masalah yang biasanya terjadi akibat pengepresan lapisan dalam, yaitu terdapat gelembung-gelembung pada bahan, bahan berubah warna, mengkilap, dan terlihat titik-titik noda. Efek yang ditimbulkan tersebut terutama pada kain jenis polyester, karena kain yang terbuat dari serat polyester apabila dilakukan uji bakar dalam arti mengalami suhu yang terlalu panas akan menjadi menyusut dan meleleh menjadi bentuk menyerupai plastik. Suhu yang tidak tepat dalam proses pengepresan dapat menyebabkan timbulnya warna kekuning kuningan dan mengalami penggelembungan (bubbling).

\section{Hasil Bustier}

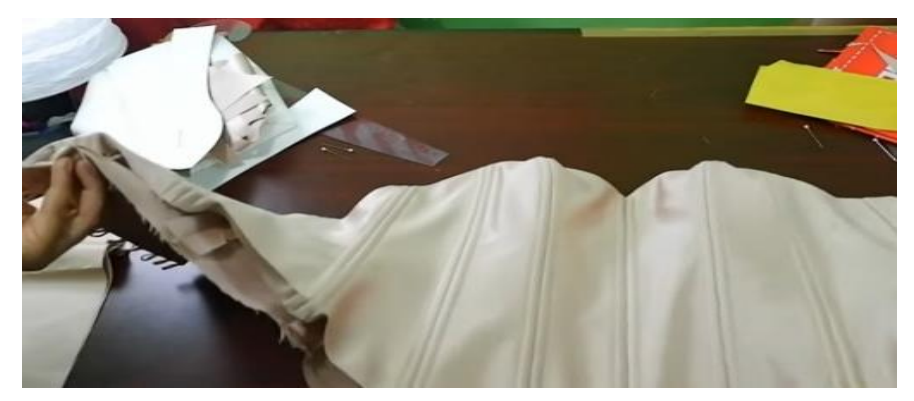

Gambar 1. Hasil Buster

Kebaya merupakan salah satu warisan nilai luhur dari nenek moyang yang juga salah satu kebudayaan asli Indonesia (Teknik, Teknik, and Surabaya 2013). Kebaya memerlukan hasil jadi yang pas membentuk lekuk tubuh sehingga memerlukan ukuran yang pas sesuai orang yang 
mengenakannya (Pkk et al. 2020). Bustier merupakan jenis pakaian wanita yang relatif ketat yang biasanya atau secara tradisional dikenakan sebagai pakaian dalam. Bustier mempunyai keunggulan pada siluetnya yang tegas. Bustier mempunyai fungsi yaitu membentuk tubuh agar lebih proporsional pada saat memakai kebaya. Pemaparan di atas dapat disimpulkan bahwa hasil bustier merupakan sesuatu yang terlihat pada permukaan bustier. Pengepresan lapisan dalam (fusing) adalah proses merekatkan (memanaskan dan mengepres) komponen-komponen kecil pada pakaian seperti collar, cuff, centerline, dan sebagainya dengan material atau bahan pelapis (interfacing) yang berfungsi sebagai pembentuk untuk membuat pakaian lebih kaku, kuat dan mengokohkann bagian-bagian tertentu.

Hasil yang dimaksud dalam penelitian ini adalah hasil permukaan kain setelah mengalami proses pengepresan lapisan dalam dengan menggunakan empat teknik pengepresan lapisan dalam, dalam arti sesuatu yang terlihat pada permukaan kain setelah mengalami proses penempelan (pengepresan) lapisan dalam.

\section{Peralatan Pengepresan}

Setrika manual : Seterika manual (non-automatic iron) adalah seterika yang tidak memiliki pengaturan temperatur, dengan sumber panas yang berasal dari tenaga listrik atau bara arang.

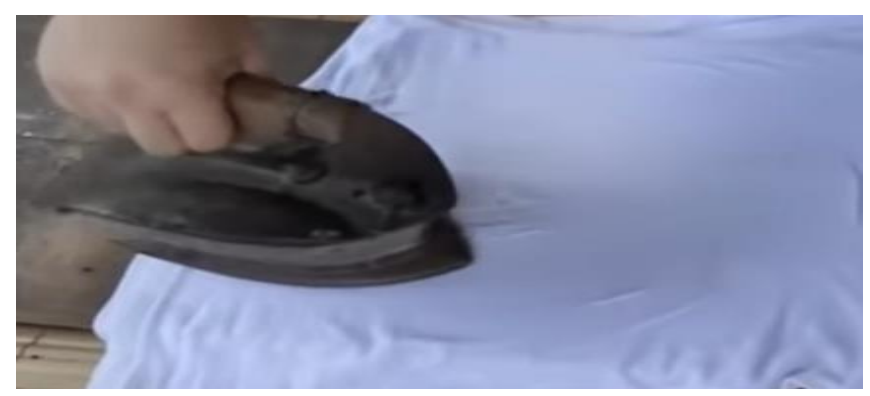

Gambar 2. Setrika Manual

Mesin Press : Mesin press merupakan mesin khusus yang digunakan untuk mengepres lapisan dalam pada bahan busana. 


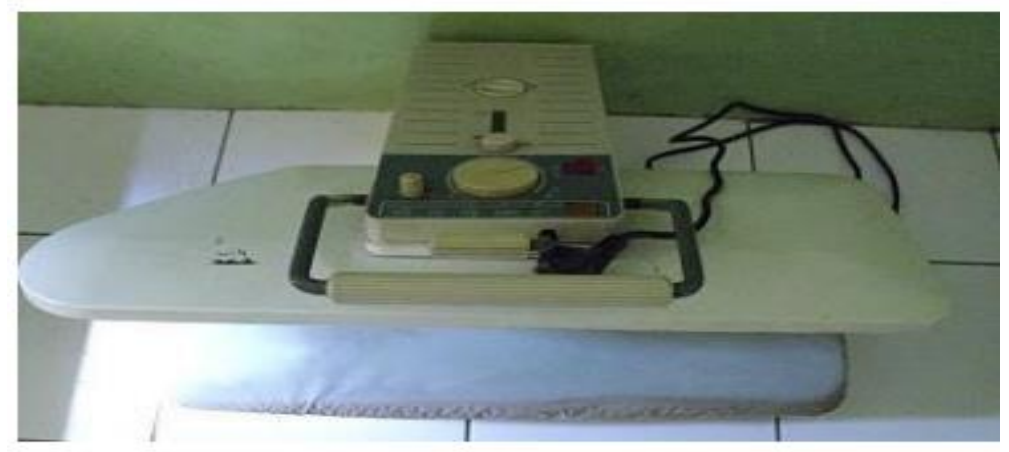

Gambar 3. Mesin Press

\section{Bahan Pelapis}

Bahan pelapis merupakan bahan yang digunakan untuk membentuk serta menopang bahan utama agar terlihat lebih kuat, stabil, rapi, dan nyaman dikenakan. Bahan pelapis umumnya berupa bahan yang kuat untuk memberikan bentuk, badan busana, serta menopang bagian-bagian kecil pakaian (pinggiran dan detail-detail). Bahan pelapis dalam penelitian ini berfungsi untuk melapisi bustier agar bentuk bustier terlihat lebih tegas, jenis bahan pelapis yang digunakan dalam penelitian ini merupakan interfacing yaitu kain gula.

\section{Pengepresan Lapisan Dalam}

Pengepresan Lapisan dalam (fusing) adalah proses merekatkan (memanaskan dan mengepres) komponen-komponen kecil pada pakaian seperti collar, cuff, centerline, dan sebagainya dengan material atau bahan pelapis (interfacing) yang berfungsi sebagai pembentuk untuk membuat pakaian lebih kaku, kuat dan mengokohkan bagian-bagian tertentu. Pengepresan lapisan dalam pada penelitian ini menggunakan empat macam cara yaitu pengepresan lapisan dalam tanpa dilapisi apapun, dilapisi kertas, dilapisi kain basah dan disemprot air.

Teknik pengepresan lapisan dalam yang biasa digunakan oleh pemroduksi busana dan juga ahli di bidang busana, diantaranya penggunaan kertas sebagai pelapis seterika ketika mengepres, tanpa dilapisi apapun ketika menempelkan lapisan dalam, penggunaan kain yang telah dibasahi, dan dengan menyemprotkan air pada bahan pelapis yang akan direkatkan pada bahan utama. Teknik pengepresan tersebut mempunyai keunggulan dan kelemahan masing-masing, bergantung padakarakteristik bahan utama yang dilapisi bahan pelapis setelah dilakukan pengepresan bahan 
pelapis. Teknik pengepresan yang telah dipaparkan di atas dapat digunakan sebagai alternatif untuk melakukan proses melekatkan bahan pelapis, sesuai dengan bahan utama yang biasa digunakan untuk membuat bustier yaitu kain dari serat poliester tenunan satin (Yudiyanti 2013).

\section{SIMPULAN}

Pengepresan lapisan dalam berperan penting terhadap hasil bustier. Ketersediaan mesin press pada modiste dan Mahasiswa Prodi Pendidikan Tata Busana terbatas, seterika listrik manual merupakan alat yang biasa digunakan untuk melakukan pengepresan, berbagai bahan digunakan untuk membuat bustier, karakteristik setiap bahan yang berbeda-beda terutama bila terkena panas. Masalah sering yang timbul setelah pengepresan lapisan dalam akibat panas yang tidak sesuai diantaranya timbul gelembung, warna kain berubah, arah serat berubah, dan sisa lem timbul pada bagian baik kain. Muncul berbagai teknik pengepresan lapisan dalam, yaitu dilapisi kain basah, disemprot air, dilapisi kertas, dan tanpa dilapisi apapun yang memiliki keunggulan dan kelemahan masing-masing, bermacam-macam teknik pengepresan lapisan dalam diharapkan dapat memperkecil masalah yang timbul pada pengepresan lapisan dalam.

Kesimpulan dalam penelitian ini, pada pengepresan dengan dilapisi kain basah mendapatkan hasil yang terbaik. Saran yang perlu disampaikan adalah hasil terburuk terdapat pada pengepresan tanpa dilapisi apapun, suhu yang digunakan pada pengepresan lapisan dalam ini kurang menghasilkan panas yang lebih, sehingga proses pengepresan lebih lama dan penelitian lanjutan dapat menerapkan bahan pelapis selain kain gula yang biasa digunakan untuk bustier yang akan menghasilkan hasil berbeda.

\section{DAFTAR PUSTAKA}

Apriliani, Dede, Pendidikan Program, Studi Pendidikan, and Tata Busana. 2016. "Perbedaan Hasil Bustier Ditinjau Dari Bahan Pelapis (Interfacing) Dan Teknik Pengepresan Lapisan Dalam.”

Di, Butik, and S M K Negeri. 2014. "REWARD PADA SUB KOMPETENSI MENJAHIT BUSTIER SISWA KELAS XI BUSANA Ratih Safitri Ratna Suhartini Abstrak.” 03.

Fergusson, Malcolm et al. 2013. "Title." Journal of Chemical Information and Modeling 53(9): 1689-99.

Khoiriyah, Anisaul, and Musdalifah Musdalifah. 2020. "Perbedaan Hasil One Shoulder Dress Ukuran M Ditinjau Dari Bahan Thai Silk, Rayon, Dan Polyester." TEKNOBUGA: Jurnal 
Teknologi Busana dan Boga 8(1): 31-37.

Napitu, Nurmaya. 2011. "PERBEDAAN MUTU HASIL JAHITAN BUSTIER YANG MENGGUNAKAN 8 GARIS PRINCESS DAN 6 GARIS PRINCESS PADA WANITA BERTUBUH GEMUK." : 37-40.

Penelitian, Latar Belakang. 2008. "Bab I ." : 1-120.

Pkk, Prodi et al. 2020. "MENGGUNAKAN POLA ARUM ( STUDI KASUS LKP ARUM KOTA TEGAL )."

Teknik, Fakultas, Fakultas Teknik, and Universitas Negeri Surabaya. 2013. "Rinda Indriana B." 02: 7-13.

Yudiyanti, Cesaria. 2013. "Pengaruh Temperatur Dan Waktu Pengepresan Lapisan Dalam ( Interfacing ) Terhadap Kualitas Bahan Jas." 